\title{
Effects of nanocomposite polymer flooding on Egyptian crude oil recovery
}

\author{
M. E. Helmi ${ }^{1}$ (D) M. Abu El Ela ${ }^{2}$ S. M. Desouky ${ }^{1}$ M. H. Sayyouh ${ }^{2}$
}

Received: 16 February 2020 / Accepted: 15 July 2020 / Published online: 18 August 2020

(c) The Author(s) 2020

\begin{abstract}
In this work, a laboratory study of enhanced oil recovery (EOR) was carried out using Egyptian crude oil of $37^{\circ} \mathrm{API}$ extracted from a reservoir in the Western Desert to identify the optimum conditions for the application of locally prepared nanocomposite polymer flooding under harsh reservoir condition. In contrary to the other studies, we tested the ability of nanocomposite polymer where nanoparticles are involved in the polymer matrix during polymerization process. Measurements of viscosity and shear rate of several solutions were taken. Displacement runs were conducted at different conditions of nanocomposite polymer salinities $(10,000,20,000,30,000,40,000,50,000,60,000$ and 65,000 ppm), concentrations (1, $1.5,2,2.5,3,3.5$ and $4 \mathrm{~g} / \mathrm{L}$ ) and slug sizes (0.2, 0.4, 0.6 and $0.8 \mathrm{PV}$ ). A linear sandpack (length of $62.5 \mathrm{~cm}$ and diameter of $2^{\prime \prime}$ ) was prepared and wrapped with thermal jacket to simulate several reservoir temperatures. It was filled by selected sand size to produce linear sandpack model with reasonable porosity $(22 \%)$ and permeability $(129-157 \mathrm{mD})$ values. The model was used to perform several displacements runs for waterflooding and nanocomposite polymer flooding. The results of the flood runs are analyzed using the water-oil relative permeability curves. The measurements of the solutions properties showed that the critical concentration of the used nanocomposite polymer in the solution is $2 \mathrm{~g} / \mathrm{L}$. Also, it was observed that the used nanocomposite polymer solution could withstand a salinity of $60,000 \mathrm{ppm}$. As a result of the flooding, it was found that the optimum economical slug size of the used nanocomposite polymer is $0.4 \mathrm{PV}$ at reservoir temperature of $40{ }^{\circ} \mathrm{C}$. The results indicated also that the used nanocomposite polymer could withstand a reservoir temperature of $90{ }^{\circ} \mathrm{C}$. The water-oil relative permeability curves showed an enhancement of oil relative permeability and a decrease in the water relative permeability using nanocomposite polymer over waterflooding. The cost of the used nanocomposite polymer with a concentration of $2 \mathrm{~g} / \mathrm{L}$ and slug size of $0.4 \mathrm{PV}$ is $0.626 \$$ for each barrel of the incremental oil recovery. Based on the results of this work, it is clear that involving nanoparticles such as silica in the polymer matrix composition improves its properties, thermal and salinity resistivity. Such study is an original contribution to carry out successful nanocomposite polymer EOR projects.
\end{abstract}

Keywords Nanocomposite polymer $\cdot$ Critical concentration $\cdot$ Optimum slug size $\cdot$ Economics analysis

\section{Introduction}

Recently, nanotechnology is considered as one of the most interesting areas for current research and development in all technical branches especially oil and gas branch. Hence, polymer nanocomposites based on nanoparticles such as silica, aluminum and copper in their structure can be considered as a new highly effective oil displacement agent (Paul

\footnotetext{
M. E. Helmi

maryanaemad@gmail.com

Egyptian Petroleum Research Institute, Cairo, Egypt

2 Faculty of Engineering, Cairo University, Giza, Egypt
}

and Robeson 2008; Matteo et al. 2012; Abu El Ela 2014). Combining and involving nanoparticles with the polymer matrix is a pathway to overcome and transcend some of the traditional chemical EOR challenges (Sayyouh et al. 1982; Adil et al. 2018). The challenges of the chemical flooding, especially polymer, can be represented by degradation of the injected chemicals under high reservoir temperatures and salinities (Sayyouh 1982; Skauge et al. 2010). As a result of these challenges, the need for new effective, environmentally friend and less costly agent has risen. There are few available studies summarize the performance of the nanocomposite polymers in enhancing oil recovery. However, there are many parameters may influence these developed nanocomposite polymers such as shear rate value, molecular

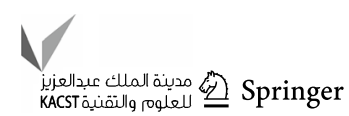


weight, nanoparticles type, polymer and nanoparticles concentrations, temperature and $\mathrm{NaCl}$ concentration. Another significant parameter effects on the feasibility study of applying polymer or nanocomposite polymer flooding projects are polymer retention and adsorption in porous media along with the damage that might occur as a result of injecting such viscous fluids. Skauge et al. observed that more than $20 \%$ reduction in the residual oil saturation occurred, when silica nanoparticles were dispersed in 600 ppm hydrolyzed polyacrylamide (HPAM) solution with $0.5 \mathrm{wt} \% \mathrm{NaCl}$ (Nguyen et al. 2012). Nguyen et al. prepared and reported the syntheses of $\mathrm{SiO}_{2}$ nanoparticles core-polymer shell and surfactants to be used for EOR applications (Maghzi et al. 2013). Flooding of $200 \mathrm{ppm}$ nanocomposite polymer and $800 \mathrm{ppm}$ surfactants, on fractured granite core plug at $92{ }^{\circ} \mathrm{C}$ with $3.44 \mathrm{wt} \%$ salinity, resulted in an increase of $6 \%$ incremental oil recovery (Maghzi et al. 2013). Also, Maghzi et al. concluded that the nanosuspension polymer solution viscosity was higher than polymer solution viscosity at the same shear rate. In addition, a 10\% increase in the oil recovery using nanosuspended polymer flooding was reported compared to the polymer flooding (Zeyghami et al. 2014). Zeyghami et al. studied experimentally the performance of hydrolyzed polyacrylamide and sulfonated polyacrylamide solutions after adding untreated hydrophilic fumed silica to enhance their thickening behavior at different solution salinities. They observed that the untreated silica addition did not improve the HPAM salinity resistivity; however, the silica-HPAM solution viscosity vanish was recorded at $4000 \mathrm{mg} / \mathrm{L}$ and salinity at $7.34 \mathrm{~S}^{-1}$. Therefore, they recommended surface treatment of silica surface by attaching hydrophobic group to reduce interactions between polymer and silica particles (Cheraghian et al. 2013). In another research work, Cheraghian investigated experimentally the benefits of using nanoclay-polymer flooding over the traditional polymer flooding in high-temperature and high salinity conditions (Sun et al. 2017). Clay nanoparticles with size less than $50 \mathrm{~nm}$ were used in this research. He observed that supplying polymer solution with nanoclay particles was positively affected the solution viscosity at $25^{\circ} \mathrm{C}$ and $80^{\circ} \mathrm{C}$. $\mathrm{He}$ remarked also that applying nanoclay polymer flooding increased oil recovery from core plug at $85^{\circ} \mathrm{C}$, compared to polymer flooding, by $11 \%$ in low salinity condition and $5.8 \%$ in high salinity condition (Sun et al. 2017). Shamilov et al. prepared and tested the performance of nanocomposites, based on carboxymethylcellulose and polyacrylamide with $\mathrm{Al}$ and $\mathrm{Cu}$ nanoparticles $(50-70 \mathrm{~nm})$, in a pilot project at Bibiheybat field of Baku. They applied their test within four continuous injection scenarios with different mixtures. By the end of their research, they recommended usage of polymers polyacrylamide with $\mathrm{Al}$ nanoparticles over the carboxymethylcellulose with nanoparticles in enhancing more crude oil recovery (Matteo et al. 2012). Therefore, nanoparticles can be involved in polyacrylamides structure, forming nanocomposite polymers, to overcome the negative impact of salinity and temperature on polymeric fluids used for enhancing oil recovery (El-Hoshoudy et al. 2016). The main purpose of the current study is to experimentally investigate the effects of nanocomposite polymer flooding on Egyptian crude oil recovery at several operating conditions using sandpack model. The effects of solution concentrations and salinity on the nanocomposite polymer properties will be elaborated. The effects of slug size and temperature on the oil recovery improvement will be studied. Extensive work will be done to determine the optimum and critical conditions of using nanocomposite polymer solution. Several laboratory flood runs at different conditions will be carried out on sandpack model.

\section{Experimental setup and material}

Crude oil sample of $37.26^{\circ} \mathrm{API}$ was used in this study. The crude oil belongs to an Egyptian oil reservoir at the Western Desert. SARA analysis was carried out for the crude oil sample using open-column chromatography gravimeter. It was found that the crude oil sample contains $39.6 \%$ (from its weight), saturates, $17.67 \%$ aromatics, $41.8 \%$ resins and $0.83 \%$ asphaltenes. This low weight percent of asphaltenes makes the crude oil sample suitable for applying nanocomposite polymer flooding. The temperature of this reservoir is $40^{\circ} \mathrm{C}$. The physical properties of the crude oil are summarized in Table 1.

Hydrolyzed polyacrylamide (HPAM) nanocomposite polymer type of molecular weight of $0.93 * 106 \mathrm{gm} / \mathrm{mol}$ was used. This nanocomposite polymer type was developed and prepared by EPRI research team (El-Hoshoudy et al. 2016).

Displacement apparatus was developed to achieve the objective of this study. The setup of the apparatus is shown in Fig. 1. It consists of six main components as follows:

1. Positive displacement pump: It can deliver pressure up to $15,000 \mathrm{psi}$ and flow rate up to $50 \mathrm{~mL} / \mathrm{min}$.

Table 1 Physical properties of the crude oil

\begin{tabular}{ll}
\hline Property & Value \\
\hline Density, gm $/ \mathrm{mL}$ & 0.8376 \\
API, ${ }^{\circ}$ & 37.26 \\
Oil viscosity @ $40^{\circ} \mathrm{C}, \mathrm{cP}$ & 4.48 \\
SARA analysis, wt $\%$ & 39.6, \\
& 17.67, \\
& 41.8, \\
& 0.83 \\
Wax content, wt $\%$ & 4.24 \\
\hline
\end{tabular}




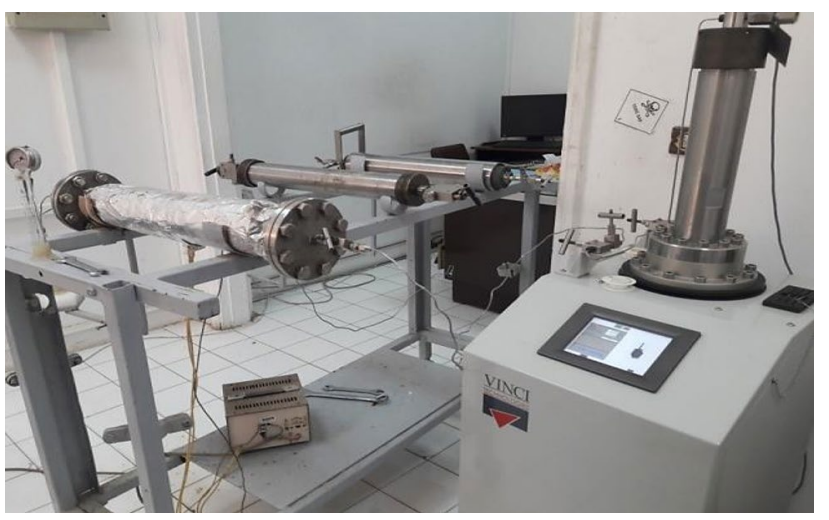

Fig. 1 Assembly of the displacement apparatus

Table 2 Properties of the sandpack

\begin{tabular}{ll}
\hline Property & Value \\
\hline Sand size, mm & 0.63 \\
Pore volume, mL & $260-280$ \\
Bulk volume, mL & 1267 \\
Porosity, \% & $20.5-22$ \\
Absolute permeability, $\mathrm{mD}$ & $129-157$ \\
Initial water saturation, \% & $21.2-23.2$ \\
\hline
\end{tabular}

2. Linear model: It was developed to simulate the reservoir rock. It is high-grade anti-corrosion stainless steel model with two end caps secured with nuts and bolts to ensure tightening. The length of the model is $62.5 \mathrm{~cm}$ and its diameter is $2 "$. It was filled by selected sand size to produce linear sandpack model with reasonable porosity and permeability values. This model can stand for pressure up to $2000 \mathrm{psi}$ and temperature up to $150{ }^{\circ} \mathrm{C}$. Table 2 summarizes the characteristics of the linear sandpack model. Injection and production ports are provided to allow fluids flow through the model. At these two ports, there are two filters to prevent sand migration during fluids flow through the model. There is a pressure gauge ranged from $(0-1000 \mathrm{psi})$ installed at the production port of the model to detect the outlet pressure. The inlet pressure is detected through the positive displacement pump pressure sensor and displayed on its control panel touch screen

3. Heating box: It can be adjusted to rise temperature up to $400{ }^{\circ} \mathrm{C}$.

4. Thermal jacket: It is an aluminum foil sheet wrapped around the stainless steel model to warm it up. It conducts heat and captures heat in an envelope around the model.

5. Accumulators (oil accumulator, chemicals accumulator, and saline water accumulator): These floating piston accumulators are used to store and inject crude oil and chemicals into the model.

6. Graduated cylinders: It is used to collect the produced fluid during the displacements runs.

At the preparation step of the sandpack, packing, hammering and filling of the model were done several times. Besides, porosity and absolute permeability of the sandpack were measured at each installation step. The sand used in this sandpack model was synthesized from sieved fractions of Egyptian core plug. Prior to sieving, the core plug was washed using diluted hydrochloric acid. Then, the core plug was dried in the oven for two days. After washing, cleaning and drying of the sand plug, sieving analysis was done using Tyler Ro-Tap shaker to get well sorted $0.63 \mathrm{~mm}$ sand size. This well-sorted sieved sand was well packed using saline water to produce linear sandpack model with reasonable porosity and permeability values. The porosity of this sandpack model was determined using the fluid saturation method. After performing the porosity measurement, the sandpack model absolute permeability was measured by steady-state method using saline water $(35,000 \mathrm{ppm})$. The flooding tests have been carried out at irreducible water saturation. Therefore, the sandpack model ought to be $100 \%$ saturated with crude oil and saline water. The following steps were conducted to determine the initial water saturation in the model:

- As the sandpack model was $100 \%$ saturated with brine solution from the recent steps, crude oil was injected with constant rate to displace the brine solution and saturate the model

- Persistent crude oil injection was carried out till producing all movable water and large amount of the injected crude oil which was equivalent to $1 \mathrm{PV}$

- The displaced water volume was measured to determine the initial oil saturation and thus initial water saturation

- Initial water saturation percentage was obtained for several runs

This procedure was carried out till achieving agreement closeness between the results of each measurement to be within the ranges shown in Table 2. Furthermore, the sand used in any flood run was replaced by new clean sand, and repacking of the model was carried out before applying another displacement run. The reproducibility tests were carried out before any flooding run to sustain the sandpack quality and consistency. The saturation of the fluid inside the model was adjusted to start flooding at the original reservoir state so that the water saturation is equal to the irreducible water saturation and the rest of the pore volume are occupied with crude oil. 


\section{Experimental work}

\section{Solution properties measurements}

Nanocomposite polymer solution samples were prepared using different concentrations of the nanocomposite polymer $(1,1.5,2,2.5,3,3.5$ and $4 \mathrm{~g} / \mathrm{L})$ at salinity of $30,000 \mathrm{ppm}$. These samples were subjected to viscosity analysis test (Mansour et al. 2018; El Aily et al. 2019). The viscosity measurements were taken at the reservoir temperature, atmospheric pressure and different shear rates. These measurements were aimed to determine the critical nanocomposite polymer concentration that could be used in the rest of the experimental tests.

After identifying the critical nanocomposite polymer concentration, several nanocomposite polymer aqueous solutions were prepared using distilled water with $(10,000$, 20,000, 30,000, 40,000, 50,000, 60,000 and 65,000 ppm) solution salinity and optimum nanocomposite polymer concentration. The viscosity measurements were taken for all of these different saline solutions and tap water (1000 ppm)-based solution. These tests were carried out, at the reservoir temperature, atmospheric pressure and different shear rates, to determine the highest salinity that nanocomposite polymer could withstand.

\section{Displacement runs}

\section{Waterflooding}

The sandpack model was prepared and installed with the rest of the displacement apparatus components to start the flood runs program. To simulate reservoir conditions, the heating box temperature was regulated to be $40{ }^{\circ} \mathrm{C}$. A thermometer was installed between the thermal jacket and the stainless steel linear model to monitor the temperature. After some hours of the temperature stabilization, the waterflooding test was carried out using 30,000 ppm saline water. The waterflooding run was conducted using constant injection rate which was $3 \mathrm{~mL} / \mathrm{min}$. Water was continuously injected till no more oil (or $<1 \mathrm{~mL}$ ) produced from the sandpack. The produced oil and water, as a result of the waterflooding, were collected in different graduated tubes. The collected oil volumes have been recorded. Besides, water breakthrough has been recorded. The residual oil saturation was also determined by the end of the waterflooding process. The waterflooding process was contributed in developing the water/oil relative permeability curve. Also, the residual oil saturation from the secondary flooding method was determined to be compared with the chemical flooding methods.

\section{Nanocomposite polymer flooding}

The nanocomposite polymer flood runs were carried out with $3 \mathrm{~mL} / \mathrm{min}$ injection rate at $40{ }^{\circ} \mathrm{C}$ using different slug sizes $(0.2,0.4,0.6$ and $0.8 \mathrm{PV})$ of the prepared nanocomposite polymer solution with the critical nanocomposite polymer concentration and 30,000 ppm salinity. Before each flood run, the sandpack was prepared. The purpose of these flood runs was to determine the optimum nanocomposite polymer solution slug size, the residual oil saturation after each slug size run and the water/oil relative permeability curve of each displacement run. The results of the flood runs have been recorded and compared. After identifying the optimum nanocomposite polymer slug size, other several nanocomposite polymer flood runs were carried out at other temperatures $\left(60,80,90\right.$ and $\left.100{ }^{\circ} \mathrm{C}\right)$ to determine the highest temperature that nanocomposite polymer could stand for at the optimum nanocomposite polymer slug size. The results of these experimental flood runs have been recorded as well.

\section{Results and discussion}

\section{Nanocomposite polymer solution measurements}

\section{Effect of nanocomposite polymer concentration}

The viscosity measurements at different nanocomposite polymer concentrations, atmospheric pressure and reservoir temperature $\left(40^{\circ} \mathrm{C}\right)$ are shown in Fig. 2. As shown in this figure, the nanocomposite polymer is working as a non-Newtonian fluid of a power law to enhance the mobility (Pascal and Pascal 1985). Also, the viscosity increases with increasing the concentration of the nanocomposite polymer in the solution sample. An increase in the nanocomposite polymer concentration from 1 to $2 \mathrm{~g} / \mathrm{L}$ is represented by approximately convergent viscosity curves, while more divergent viscosity curves are perceived above $2 \mathrm{~g} / \mathrm{L}$ nanocomposite polymer concentration. This sudden change of the viscosity curves can be analyzed as a result of changing the nanocomposite polymer phase from viscous to elastic phase (Bird et al. 1983; Larson 1999). The critical nanocomposite polymer concentration could be determined using this Cartesian plot supported by another $\log -\log$ plot of the viscosity curves. These data are rearranged and plotted as shown in Fig. 3. The viscosity curves are converted to two intersection lines with different slopes on this log-log plot. The intersection point of these lines at all applied shear rates is at $2 \mathrm{~g} / \mathrm{L}$ nanocomposite polymer concentration. Hence, the critical nanocomposite polymer concentration is $2 \mathrm{~g} / \mathrm{L}$. 
Fig. 2 Effect of nanocomposite polymer concentration on the solution viscosity at $40{ }^{\circ} \mathrm{C}$ and different shear rates

Fig. 3 Log-log plot of apparent polymer solutions viscosity vs. polymer concentration at $40{ }^{\circ} \mathrm{C}$ and different shear rates
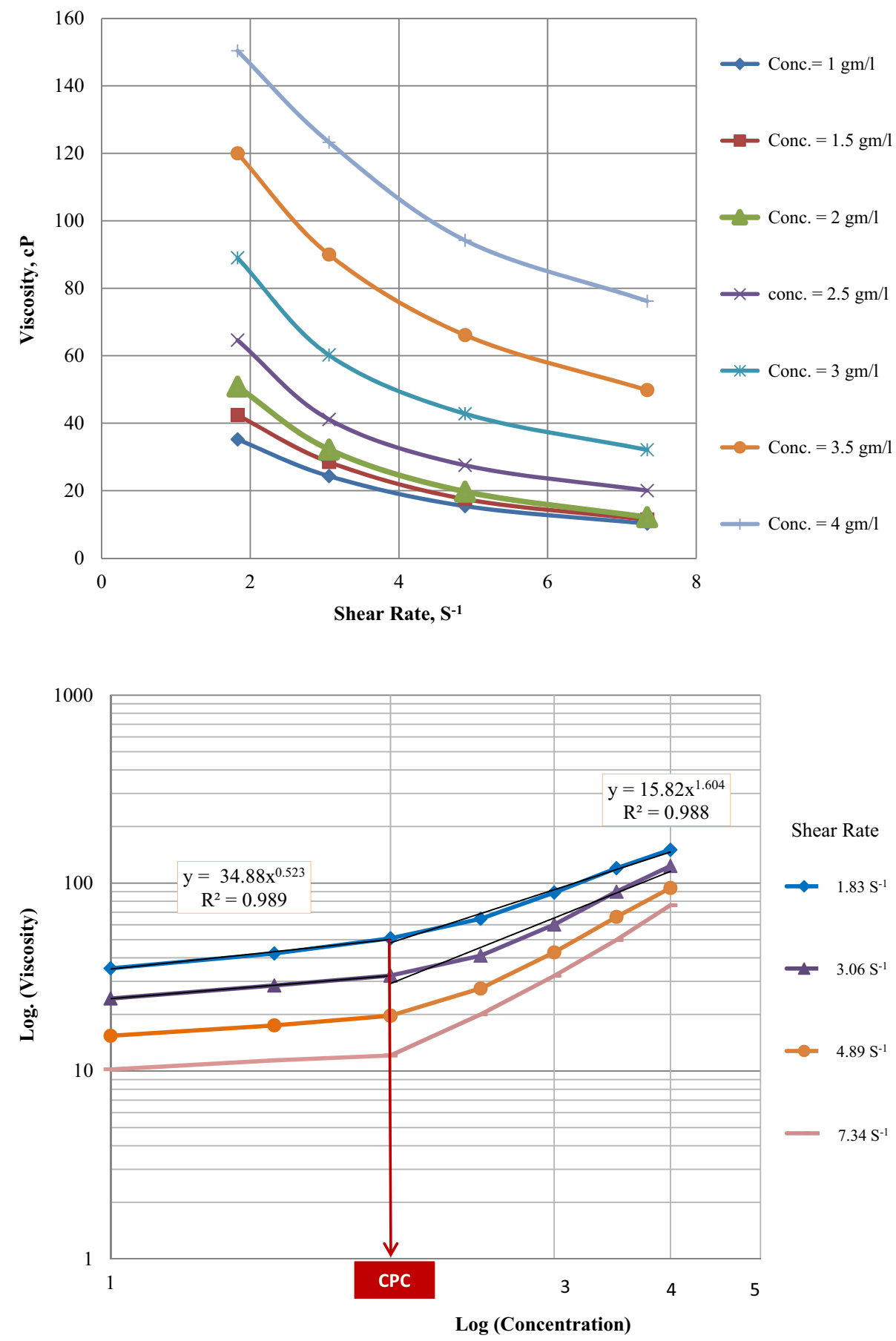

\section{Effect of nanocomposite polymer solution salinity}

The viscosity measurements at different nanocomposite polymer solution of salinity of $(1000,10,000,20,000,30,000$, $40,000,50,000,60,000$ and $65,000 \mathrm{ppm})$, atmospheric pressure and reservoir temperature of $40{ }^{\circ} \mathrm{C}$ along with critical nanocomposite polymer concentration of $2 \mathrm{~g} / \mathrm{L}$ are shown in Fig. 4. As shown in this figure, the nanocomposite polymer solutions viscosity decreased with increasing solutions salinity. Furthermore, a sudden drop in viscosity measurements was observed after a solution salinity of $60,000 \mathrm{ppm}$. This result might be related to that the nanocomposite polymer solution withstand till a salinity of $60,000 \mathrm{ppm}$. With a salinity above $60,000 \mathrm{ppm}$, the nanocomposite polymer viscosity degradation might be occurred. 
Fig. 4 Effect of solution salinity on the nanocomposite polymer solution viscosity at $40^{\circ} \mathrm{C}$ and different shear rates

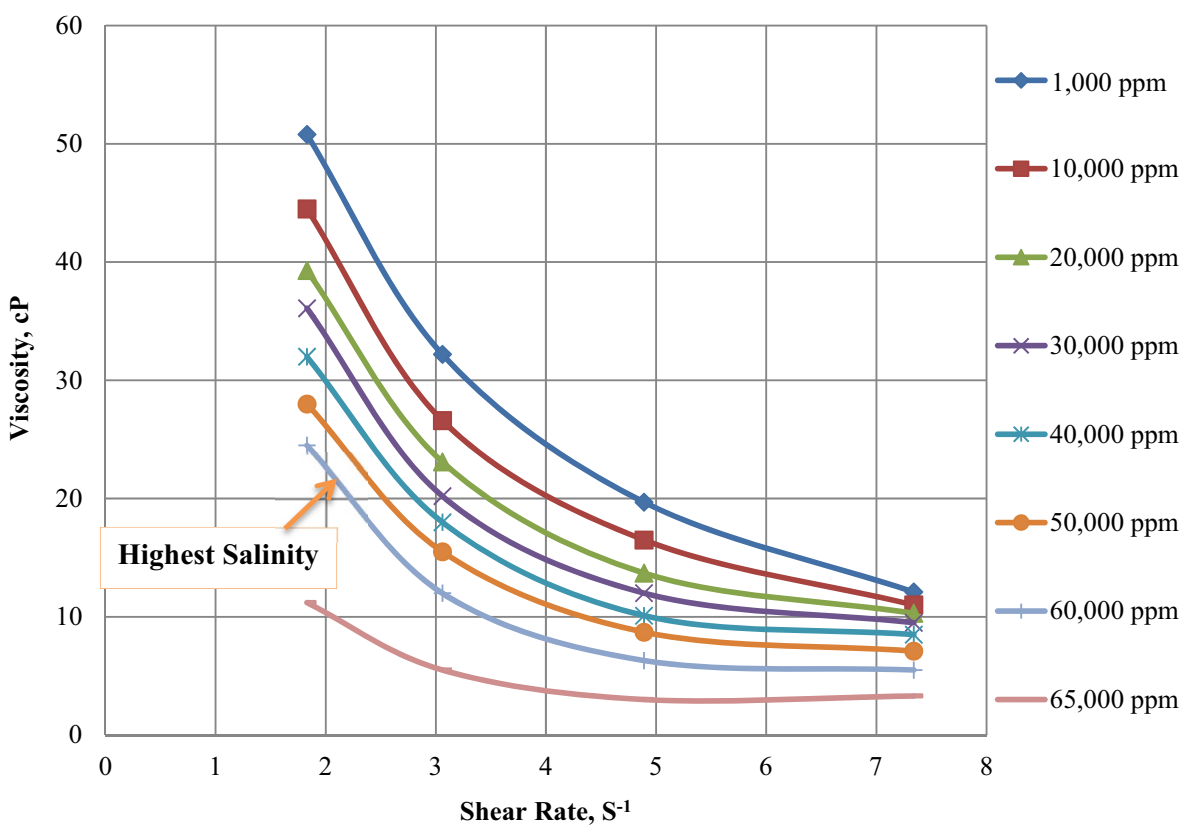

\section{Results of the displacement runs}

\section{Results of the waterflooding tests}

The cumulative oil recovery till injection of $2 \mathrm{PV}$ of saline water $(30,000 \mathrm{ppm})$ at reservoir temperature of $40^{\circ} \mathrm{C}$ is presented in Fig. 5. As shown in this figure, the saline waterflooding resulted in $46.76 \%$ cumulative oil recovery from the initial oil in place. In addition, the water breakthrough occurred at injection of $0.53 \mathrm{PV}$. It should be highlighted that there was about $41.41 \%$ oil saturation left behind the waterflooding considering that the initial/ irreducible water saturation was $22.22 \%$ at the start of the flood and the final water saturation was $58.37 \%$ at the end of the flooding run. Based on the relative permeability data of this run and the viscosity measurements, the mobility ratio with the waterflooding is 1.68 . Hence, the polymer flooding would be a preferable technique to enhance oil recovery.
Fig. 5 Cumulative oil recovery factor for waterflooding at $40{ }^{\circ} \mathrm{C}$

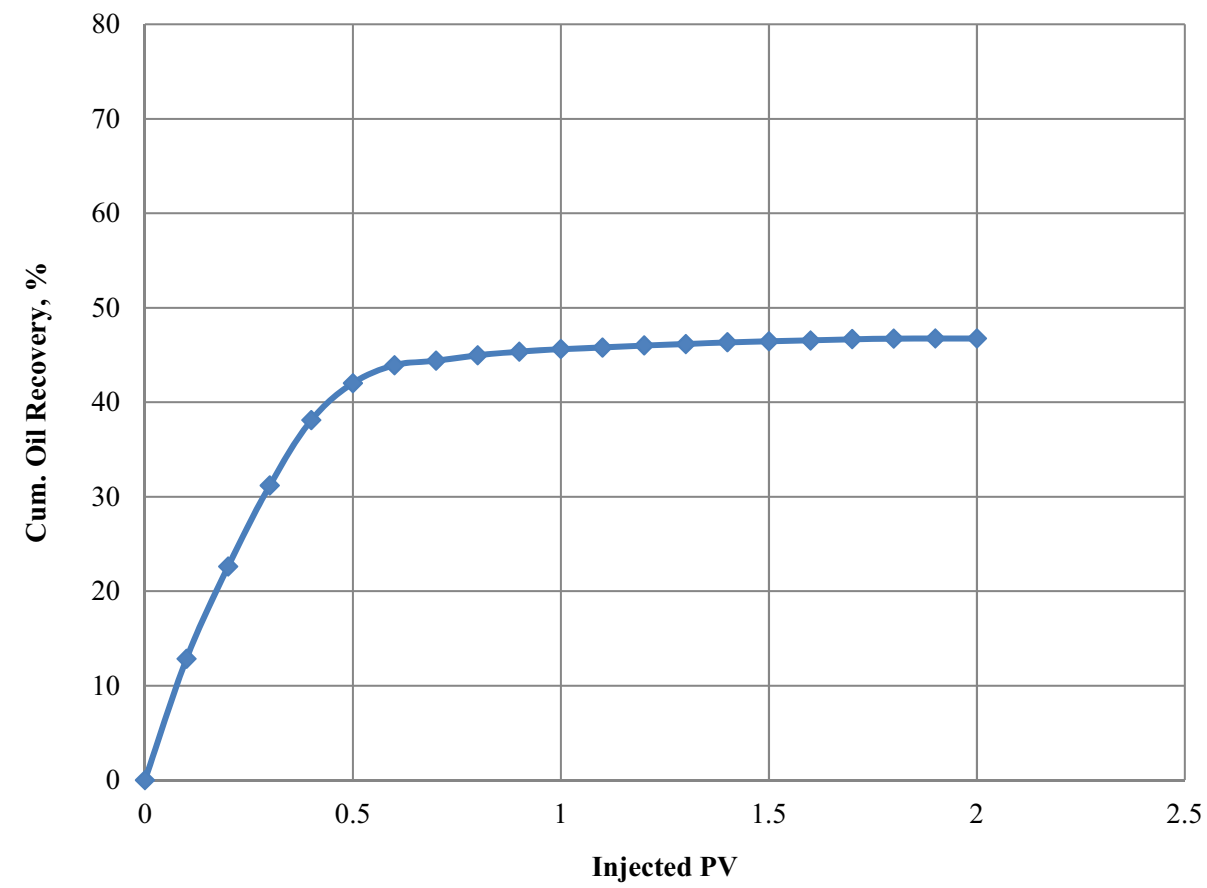




\section{Results of the nanocomposite polymer flooding runs}

Effect of the nanocomposite polymer slug size The cumulative oil recovery factor using nanocomposite polymer solution of different slug sizes $(0.2,0.4,0.6$ and $0.8 \mathrm{PV})$ with a concentration of $2 \mathrm{~g} / \mathrm{L}$ (optimum concentration) and salinity of $30,000 \mathrm{ppm}$ at a temperature of $40{ }^{\circ} \mathrm{C}$ is presented in Fig. 6. It is clear from this figure that flooding the sandpack using large slug size of nanocomposite polymer can produce higher oil recovery than the small nanocomposite polymer slug size. Nanocomposite polymer slug sizes of $0.2,0.4$, 0.6 and $0.8 \mathrm{PV}$ resulted in cumulative crude oil recovery of $79.24,88.52,92.71$ and $96.66 \%$; and water breakthrough occurred at $0.64,0.72,0.74$ and $0.78 \mathrm{PV}$, respectively.

Hence, the water breakthrough can be delayed by increasing the injected nanocomposite polymer slug size. Virtually, the optimum injected polymer slug size is critical to minimize the costs of the flooding process. To determine the optimum polymer slug size in this work, a rule of thumb of literature work was applied to achieve the maximum net cash flow (Reisberg 1972; Al-Blehed et al. 1991). The study indicates that the injected optimum slug size of the nanocomposite polymer is $0.4 \mathrm{PV}$ which resulted in $88.52 \%$ ultimate oil recovery and $0.72 \mathrm{PV}$ water breakthrough at simulated reservoir temperature, $40^{\circ} \mathrm{C}$.

Effect of the temperature The cumulative oil recovery factor using nanocomposite polymer solution of optimum slug size of $0.4 \mathrm{PV}$, optimum concentration of $2 \mathrm{~g} / \mathrm{L}$ and salinity of 30,000 ppm at different simulated temperatures of 40,60, 80,90 and $100{ }^{\circ} \mathrm{C}$ is presented in Fig. 7. As shown in this figure, rising the sandpack temperature resulted in a reduc- tion in the ultimate oil recovery using nanocomposite polymer flooding. The nanocomposite polymer flooding could result in ultimate oil recovery of $88.52 \%$ at $40{ }^{\circ} \mathrm{C}, 70.47 \%$ at $60{ }^{\circ} \mathrm{C}, 56 \%$ at $80{ }^{\circ} \mathrm{C}, 47 \%$ at $90{ }^{\circ} \mathrm{C}$ and $27.29 \%$ at $100{ }^{\circ} \mathrm{C}$. At $90{ }^{\circ} \mathrm{C}$, the nanocomposite polymer flooding resulted in approximately the same ultimate oil recovery using waterflooding. Hence, the nanocomposite polymer solution could withstand temperatures up to $90{ }^{\circ} \mathrm{C}$ not more. After this temperature, thermal degradation of the nanocomposite polymer might be occurred.

Unsteady state tests were carried out through water and nanocomposite polymer flooding runs on the linear sandpack model. The experimental data resulted from these tests were used to determine oil and water relative permeability curves at different conditions. The aim of this analysis was to detect the change in the water-oil relative permeability curves as a result of water and nanocomposite polymer displacement runs. The relative permeability curves are considered as the most relevant petrophysical relation for applying EOR methods. These relative permeability curves are generated by history matching tool to reconcile the experimental results obtained in the laboratory. Therefore, straight line relative permeability curves have been achieved in some experiments. Unsteady state water-oil relative permeability curves were produced using the waterflooding and nanocomposite polymer production data, sandpack model properties and the crude oil properties. Figure 8 presents a comparison of the water-oil relative permeability curves obtained using water and the optimum nanocomposite polymer flooding conditions (concentration of $2 \mathrm{~g} / \mathrm{L}$, slug size of $0.4 \mathrm{PV}$, salinity of $30,000 \mathrm{ppm}$ ) at temperature of $40^{\circ} \mathrm{C}$. Typically,
Fig. 6 Cumulative oil recovery factor for nanocomposite flooding at $40{ }^{\circ} \mathrm{C}$ and different injected slug sizes

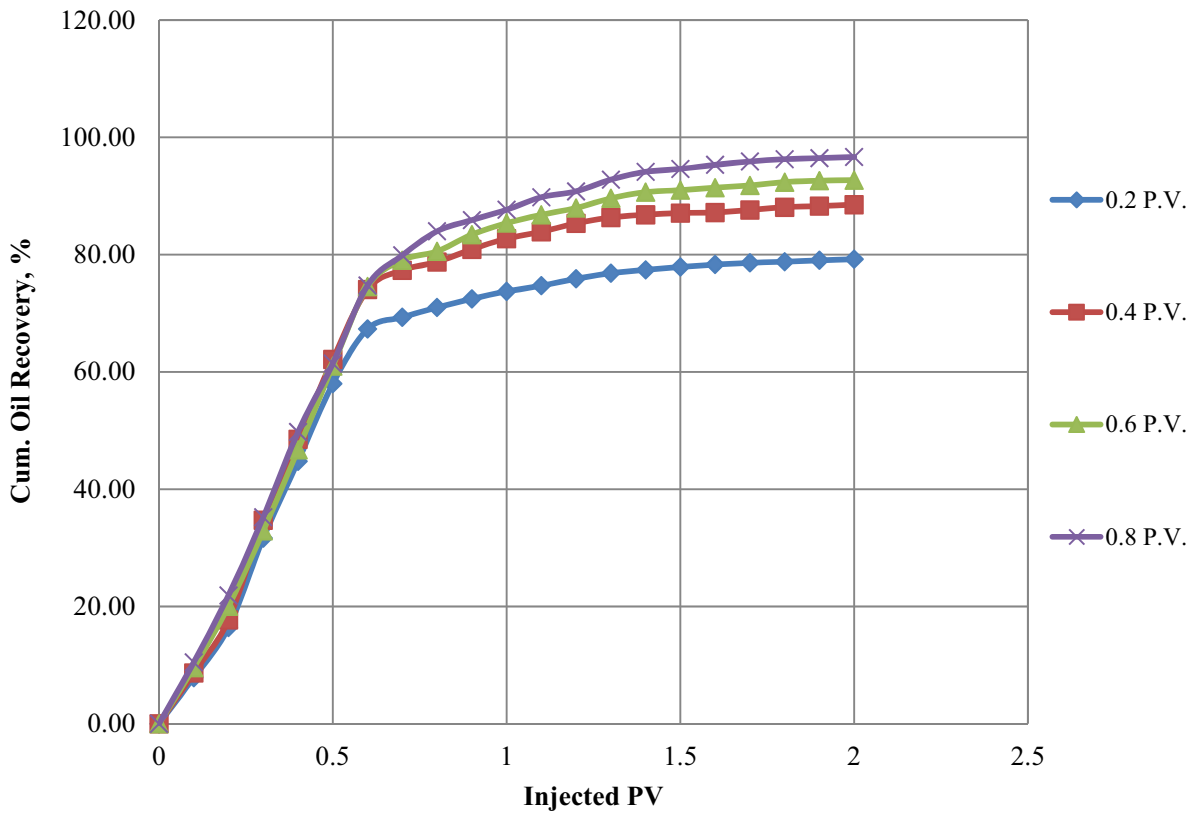


Fig. 7 Cumulative oil recovery factor for nanocomposite polymer flooding at different temperatures
Fig. 8 Comparison between water-oil relative permeability curves obtained using waterflooding and the optimum slug size of nanocomposite polymer (0.4 PV) at $40^{\circ} \mathrm{C}$
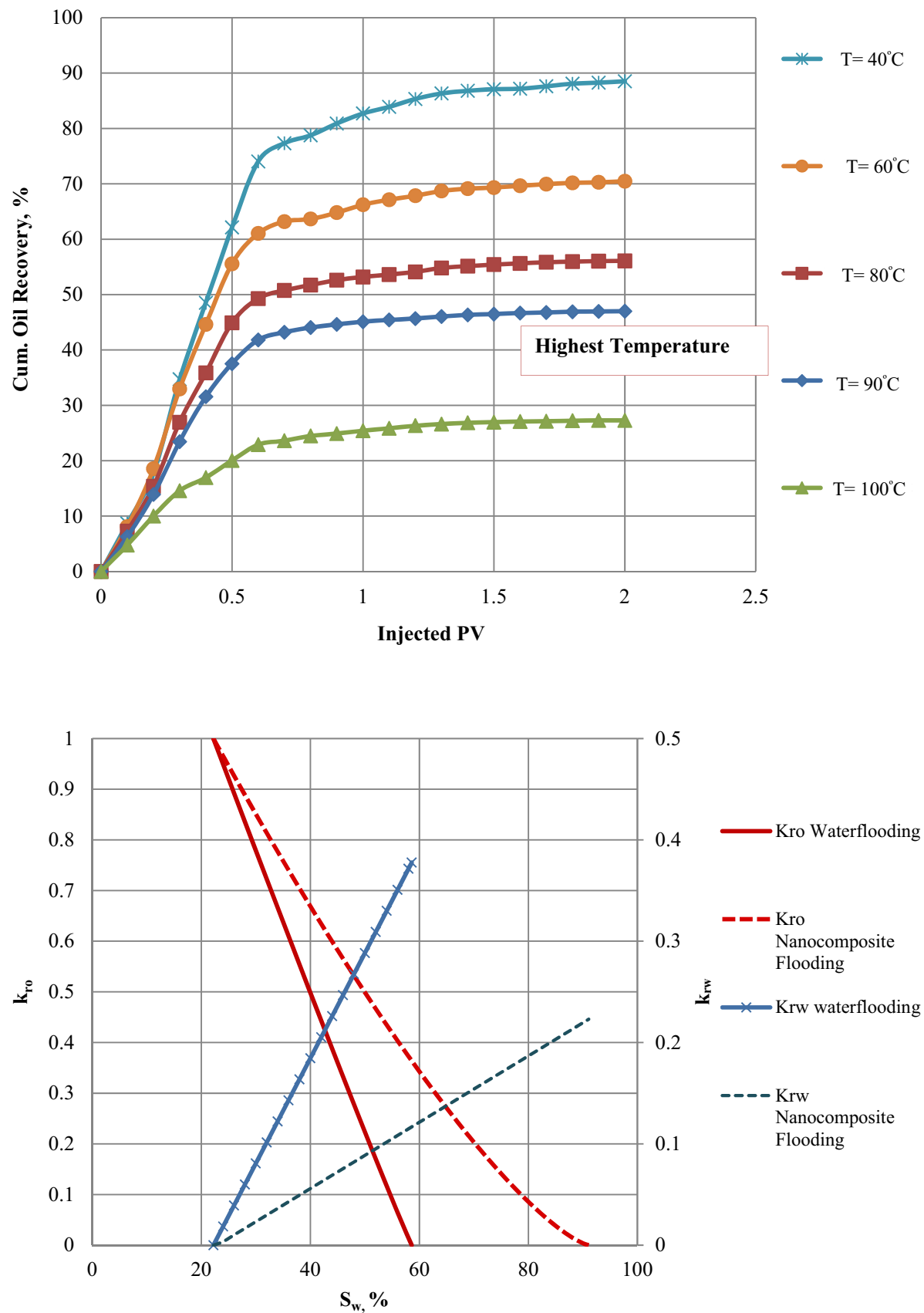

the endpoint relative permeability of the wetting phase is smaller than the non-wetting phase endpoint. Figure 8 indicates that the linear sandpack model could represent a relatively water-wet model as water permeability at $S_{\text {or }}$, 0.377 , was less than oil relative permeability at $S_{\text {wi }}$. As shown in Fig. 8, the nanocomposite polymer flooding was able to enhance the oil relative permeability curve and reduce the residual oil saturation from $41.41 \%$ with the waterflooding to be $8.93 \%$ only with the nanocomposite polymer flooding, in the laboratory scale. This indicates that inserting of nanoparticles such as silica nanoparticles into the polymer matrix improves its performance in enhancing oil recovery.

\section{Economics analysis}

It should be highlighted that an economical analysis was performed to evaluate the feasibility of the nanocomposite polymer flooding process. The study indicates that the nanocomposite polymer flooding would cost $0.626 \$ / b b l(0.626 \$$ 
for each barrel of the incremental oil recovery) based on the following data:

1. $1450 \$$ ton nanocomposite polymer price for a locally prepared nano-silica-HPAM at EPRI

2. $2 \mathrm{~g} / \mathrm{L}$ as critical nanocomposite polymer concentration

3. 0.4 PV optimum nanocomposite polymer slug size

4. $87.71 \mathrm{~mL}$ incremental oil recovery after subtracting the oil produced using waterflooding

\section{Conclusions}

1. Locally prepared nanocomposite polymer was used to show its effect on enhancing Egyptian crude oil recovery under harsh reservoir condition. We tested the ability of nanocomposite polymer where nanoparticles are involved in the polymer matrix during polymerization process.

2. The critical concentration of the used nanocomposite polymer in the solution is $2 \mathrm{~g} / \mathrm{L}$ at $40{ }^{\circ} \mathrm{C}$.

3. The nanocomposite polymer solution at the critical concentration of $2 \mathrm{~g} / \mathrm{L}$ could stand for a salinity of $60,000 \mathrm{ppm}$ at temperature of $40^{\circ} \mathrm{C}$.

4. The waterflooding process was able to achieve an ultimate oil recovery of $46.76 \%$ from the linear sandpack at $40{ }^{\circ} \mathrm{C}$.

5. The optimum slug size of the used nanocomposite polymer is $0.4 \mathrm{PV}$ which resulted in an ultimate oil recovery of $88.52 \%$ at $40{ }^{\circ} \mathrm{C}$.

6. The used nanocomposite polymer solution could withstand $90^{\circ} \mathrm{C}$. The previously prepared and studied nanocomposite polymer solutions could not withstand such temperature.

7. The oil relative permeability curve could be improved by using nanocomposite polymer flooding rather than the traditional waterflooding.

8. The cost of the used nanocomposite polymer with a concentration of $2 \mathrm{~g} / \mathrm{L}$ and slug size of $0.4 \mathrm{PV}$ is $0.626 \$$ for each barrel of the incremental oil recovery.

Open Access This article is licensed under a Creative Commons Attribution 4.0 International License, which permits use, sharing, adaptation, distribution and reproduction in any medium or format, as long as you give appropriate credit to the original author(s) and the source, provide a link to the Creative Commons licence, and indicate if changes were made. The images or other third party material in this article are included in the article's Creative Commons licence, unless indicated otherwise in a credit line to the material. If material is not included in the article's Creative Commons licence and your intended use is not permitted by statutory regulation or exceeds the permitted use, you will need to obtain permission directly from the copyright holder. To view a copy of this licence, visit http://creativecommons.org/licenses/by/4.0/.

\section{References}

Abu El Ela M, El Tayeb S, Sayyouh H (2014) An integrated approach for the application of the enhanced oil recovery projects. J Pet Sci Res 3(4):176-188

Adil M et al (2018) Experimental study on electromagnetic-assisted $\mathrm{ZnO}$ nanofluid flooding for enhanced oil recovery (EOR). PLoS ONE 13(2):e0193518

Al-Blehed $\mathrm{M}$ et al (1991) An engineering-economic evaluation of enhanced recovery of Saudi crudes by chemical flooding. Eng Costs Prod Econ 21(2): 105-109

Bird RB et al (1983) The rheology and flow of viscoplastic materials. Rev Chem Eng 1(1):1-70

Cheraghian $\mathrm{G}$ et al (2013) An experimental investigation of the enhanced oil recovery and improved performance of drilling fluids using titanium dioxide and fumed silica nanoparticles. J Nanostruct Chem 3(1):78

El-Hoshoudy A et al (2016) Use of 1-vinyl imidazole based surfmers for preparation of polyacrylamide- $\mathrm{SiO}_{2}$ nanocomposite through aza-Michael addition copolymerization reaction for rock wettability alteration. Fuel 170:161-175

El Aily M et al (2019) Modeling viscosity of moderate and light dead oils in the presence of complex aromatic structure. J Pet Sci Eng 173:426-433

Larson RG (1999) The structure and rheology of complex fluids. Oxford University Press, New York

Maghzi A et al (2013) An experimental investigation of silica nanoparticles effect on the rheological behavior of polyacrylamide solution to enhance heavy oil recovery. Pet Sci Technol 31(5):500-508

Mansour E et al (2018) The effect of asphaltene content on predicting heavy dead oils viscosity: experimental and modeling study. Fuel 212:405-411

Matteo C et al (2012) Current and future nanotech applications in the oil industry. American Journal of Applied Sciences 9(6):784

Nguyen PT et al (2012). Evaluation on the EOR potential capacity of the synthesized composite silica-core/polymer-shell nanoparticles blended with surfactant systems for the HPHT offshore reservoir conditions. SPE International Oilfield Nanotechnology Conference and Exhibition, Society of Petroleum Engineers

Pascal H, Pascal F (1985) Flow of non-Newtonian fluid through porous media. Int J Eng Sci 23(5):571-585

Paul DR, Robeson LM (2008) Polymer nanotechnology: nanocomposites. Polymer 49(15):3187-3204

Reisberg J (1972) Secondary and tertiary oil recovery process, Google Patents

Sayyouh M (1982) "A Laboratory Investigation of Enhanced Oil Recovery Methods by Chemical Solutions." CIM paper: 82-3.

Sayyouh, M., et al. (1982). Effect of salinity and temperature on polymer flooding. Journal of Canadian Petroleum Technology, Canadian inst Mining Metallurgy Petroleum 101 6th ave sw, Ste 320, calgary

Skauge T et al (2010) Nano-sized particles for EOR. SPE improved oil recovery symposium, Society of Petroleum Engineers

Sun X et al (2017) Application of nanoparticles in enhanced oil recovery: a critical review of recent progress. Energies 10(3):345

Zeyghami M et al (2014) Investigation of the applicability of nano silica particles as a thickening additive for polymer solutions applied in EOR processes. Energy Sour Part A Recovery Util Environ Eff 36(12):1315-1324

Publisher's Note Springer Nature remains neutral with regard to jurisdictional claims in published maps and institutional affiliations. 